\title{
NECROSIS OF THE BRAIN DUE TO RADIATION THERAPY CLINICAL AND PATHOLOGICAL OBSERVATIONS \\ BY
}

\author{
JOE PENNYBACKER and DOROTHŸ S. RUSSELL
}

\author{
(RECEIVED MAY 5, 1948)
}

In treating intracranial tumours with deep $x$ rays or radium the aim is to direct the largest possible dose of radiation to the tumour within the limits of safety for the normal tissues. Even with the standard dosages in current use, irradiated areas of the scalp suffer temporary or permanent epilation. Excessive radiation is known to cause burns and necrosis of the scalp and skull, and harmful effects on the underlying brain. These complications are usually manifest within a short time of treatment and they may be largely avoided by using multiple portals of entry so that no one area of the overlying or surrounding tissues receives more than a fraction of the total dose brought to bear on the tumour. In fact the technique of therapy is so well developed that serious damage to normal structures is regarded as a rare occurrence.

Nevertheless we have encountered in recent years a series of cases in which harmful effects to the brain have followed standard dosages and technique without serious superficial damage, and at long intervals after the termination of treatment. Although the effects were not strictly uniform in every case, the similarity was close enough in each, and so different from other pathological processes, that it seems reasonable to relate them to the single common feature of radiation treatment. In brief, the lesion was an extensive subcortical necrosis, maximal in the field which received the most radiation. In some cases the clinical effects came on after a long latent interval with the suddenness of a vascular accident; in - others they were slowly progressive, clinically suggesting a recurrence of the tumour for which the radiation treatment had been given. In the fatal cases the lesion seemed to be largely responsible for death.

Nine cases have been examined. Eight of these had had various surgical procedures for cerebral neoplasms followed by one or more courses of radiation treatment. The other case is of particular interest because so far as can be known the brain was normal before radiation treatment was instituted for a rodent ulcer of the scalp. This case will be described first, followed by four others which are representative of the remainder.

\section{Case Reports \\ CASE 1}

Rodent ulcer of scalp. Multiple excisions followed by $x$ radiation. Nine months later epilepsy and hemiplegia. Radium treatment of ulcer in preparation for craniotomy. Aggravation of cerebral symptoms. Operation: excision of necrotic lesion of left temporal lobe. Recovery. (R.I. 21380/44.)

A man aged 52 years was admitted to the Radcliffe Infirmary, Oxford, on Jan. 14, 1944, suffering from aphasia and epileptic attacks. At the age of 37 a warty growth was excised from the left parietal region of the scalp, above and behind the left ear. It was found to be a rodent ulcer, and recurrences were excised on several occasions, the last being in March, 1943. Immediately afterwards he was given deep $x$-ray treatment to the affected area (a single exposure of $2,300 \mathrm{r}$. The physical factors were: kV. 230 ; milliamps. 10 ; $\frac{1}{2}$ H.V.L. $1.3 \mathrm{~mm}$. of copper ; F-s distance $29 \mathrm{~cm}$. ; size of field circle $7 \mathrm{~cm}$. diameter ; time of exposure 10 minutes 12 seconds).

The scalp never quite healed, and in the three or four months before his admission to the Radcliffe Infirmary a further recurrence was obvious.

Apart from a little local discomfort at the site of the growth and the inconvenience attendant on its size and position, he had no symptoms until Dec. 19, 1943, when his speech suddenly became confused, and within a few moments his right arm began to jerk convulsively and he lost consciousness for several minutes. When he recovered, he seemed dazed and was unable to express himself in speech or writing. There was no obvious paralysis of his limbs. Another attack occurred about three hours later, and in this one he was unconscious for nearly an hour, with what was described as generalized convulsions. He was then taken to a hospital where shortly after admission he had a third attack. When he recovered consciousness he had considerable aphasia, 
but no other neurological abnormalities were detected. There was no headache or vomiting. The spinal fluid pressure was increased but the fluid was normal on analysis. It was thought that the aphasia and the epileptic attacks were due to invasion of the meninges and brain by the rodent ulcer, and arrangements were made for the patient's transfer to the Radcliffe Infirmary.

On admission he was a healthy looking man, somewhat distressed by considerable aphasia affecting all aspects of the language function. He had no recollection of the epileptic attacks or of any events for the four days following them. There was a rodent ulcer, $4 \mathrm{~cm}$. in diameter, in the left lower parietal region with a thick yellow crust in its centre. The scalp for $1 \mathrm{~cm}$. around the periphery of the ulcer was thin, shiny, and adherent to the underlying skull. The neurological examination revealed normal optic fundi, full visual fields, normal pupils and ocular movements, and slight weakness of the right side of the face and right upper limb. The tendon reflexes were slightly increased in the right upper limb, but the other reflexes were normal. There was no sensory disturbance. The spinal fluid pressure was normal $(140 \mathrm{~mm}$.) but the fluid contained $80 \mathrm{mg}$. of protein per 100 c.cm. and 4 lymphocytes per c.mm. Radiographs of the skull were normal : there was no abnormality in relation to the rodent ulcer, and the pineal shadow was situated in the middle line. The general examination was negative. The blood pressure was $130 / 90 \mathrm{~mm}$. $\mathrm{Hg}$.

The possibility of a radiation effect was considered, but it was thought that the dosage was too small and that a neoplasm or abscess related to the superficial tumour was more likely. In view of the possible need to reflect an osteoplastic flap in the vicinity of the ulcer, an attempt was made to heal the ulcer by the insertion of $40 \mathrm{mg}$. of radium needles on Jan. 25, 1944, and these were left in situ for 120 hours.

Within two days of the insertion of the radium, the patient began to deteriorate. He complained of a little headache, he was observed to be sleeping more than normally, and the aphasia and right hemiparesis became more pronounced. He seemed to resent painful stimuli less on the right side of the body than on the left, though the aphasia made it difficult to assess sensory abnormalities. There seemed to be no hemianopia. On Feb. 6, the spinal fluid pressure was $200 \mathrm{~mm}$., and the fluid now contained $180 \mathrm{mg}$. of protein per $100 \mathrm{c.cm}$. and 9 lymphocytes per c.mm. Radiographs of the skull taken on Feb. 10 showed that the pineal shadow was now displaced to the right side of the middle line.

OPERATION.-The evidence for a progressive lesion in the left cerebral hemisphere was thus clear and the possibilities of abscess or neoplasm had yet to be excluded. An arteriogram (thorotrast) was done, but the findings were not definite, so a ventriculogram was done on Feb. 10. Only the right ventricle could be found and filled with air : it was markedly displaced to the right side. In seeking the left ventricle the brain cannula met a tough resistance in the temporo-parietal region. An osteoplastic flap was reflected in the left temporo-parietal region, with the scalp ulcer-much cleaner and smaller since the application of radium -in the centre of its base.
The scalp was lightly adherent to the pericranium in the vicinity of the ulcer, but it separated easily with blunt dissection. The pericranium itself, the skull, and the dura appeared normal. When the dura was opened a lesion was clearly apparent in the posterior part of the temporal lobe, exactly underneath the rodent ulcer. In a sharply circumscribed area, $4 \mathrm{~cm}$. from before back by $3 \mathrm{~cm}$. from above down, the convolutions were broad, flat, and swollen and had a rather greasy, brownish appearance. They were very firm, almost hard to the touch. The surface blood vessels were not remarkable, but there was an excess of small visible vessels coursing over the convolutions. The surrounding brain appeared to be quite normal. A fragment of tissue was taken for rapid examination and its toughness was such that it had to be cut with a sharp knife. The provisional diagnosis at this stage was thought to be metastatic carcinoma and the mass was dissected out. The lesion looked fairly discrete but there were numerous white fibrous strands extending from the main mass out into the surrounding white matter, and these were so tough that they had to be cut with scissors. The deep surface of the mass abutted on to the wall of the ventricle in the posterior part of the temporal lobe.

SUBSEQUENT COURSE.-Convalescence was uneventful. The aphasia was much more marked for a few days after operation, but by the time he was discharged on Feb. 28 it was of about the same order as on admission. There was a complete right homonymous hemianopia. Eigh\$ months after operation the aphasia was much less marked $\overrightarrow{\widehat{P}}$ but even so prevented him from resuming work as clerk. The hemianopia was complete in the upper quadrant, incomplete in the lower. There were n£ other neurological abnormalities. He had one epileptis attack, very much like the pre-operative ones, twळ $\vec{\oplus}$ months after operation, and another minor one about six months later. There were no more up to the time of the last follow-up in November; 1947, forty-five months after operation. By this time the hemianopia had receded to a sharp upper-quadrant defect, and the aphasia had diminished to the point where it was barely detectable in ordinary conversation. He was able to resume his work as a filing clerk in June, 1947.

\section{Pathological Observations on the Spectmen RemOVED at OPERATION}

Macroscopic.-The leptomeninges were not obviously altered, but the blood vessels were engorged. The cortex on section was broadened in many places and, over the summits of the convolutions; was tough, grey, and indistinctly demarcated from the white matter. The latter was firm, unusually opaque and creamy-white throughout the specimen. It contained numerous petechial hæmorrhages, especially just beneath the cortex (Fig. 1).

Microscopic.-The leptomeninges had undergone slight fibrous thickening and were diffusely infiltrated with a few polymorphonuclear leucocytes and lymphocytes. A little recent hæmorrhage was present in places, probably the result of operative manipulation. There was slight fibrous thickening of the adventitia of a few of the larger arteries and veins. The cortex was altered 
everywhere by changes which reached their greatest intensity over the summits of the donvolutions. Thus there was a progressive loss of neurones, becoming almost complete at the summits, accompanied by gliosis that was in general dense, but less cellular over the convexities of the convolutions (Fig. 2). Surviving neurones showed dropsical swelling of the cell-body with stages of chromatolysis. In many the outlines of the cells were greatly crenated. The nuclei were frequently pyknotic. Some neurones were shrunken and hyperchromatic. The astrocytes were conspicuous for their large size and wealth of processes (Fig. 3). In certain areas they showed clasmatodendrosis with the formation of "amœboid glia." In these foci the perforating blood vessels had undergone thrombosis, and the surrounding tissue was necrotic and contained extravasated red corpuscles. Gliosis beneath the pia had resulted in a remarkable brush-like formation of the fibres (Fig. 3). In the areas of greatest destruction of neurones there was a pronounced lack both of oligodendroglia and microglia. Surviving oligodendroglial cells were hypertrophied and had well-preserved, unusually long processes. The microglial cells were in active amœboid phases and were found mostly in foci of actual necrosis and hæmorrhage. In the better preserved parts of the cortex, that is, in the depths of the sulci, many reacting microglial cells were present ; the oligodendroglial cells were still somewhat scanty and many were in advanced stages of acute swelling.

The perforating vessels were extensively altered by fibrinoid necrosis and were often thrombosed. Many were greatly engorged. Thrombosis was often accompanied by recent perivascular hæmorrhages. Almost the entire cortex was unevenly permeated by interlacing filaments of fibrin. There was no histological evidence of antecedent hæmorrhages; in particular no iron pigment was found. In some of the cortical vessels there was great fibrous thickening of the adventitia! sheaths and focal infiltration with thin cuffs of lymphocytes. Particles of thorotrast were often present in the walls of the vessels, especially in the adventitial cells.

Massive necrosis involved all parts of the white matter. It was permeated with densely matted fibrin filaments, and was unevenly infiltrated with considerable numbers of degenerating and fragmented leucocytes (Fig. 4). Many hæmorrhages were present, often surrounding vessels that had undergone fibrinoid necrosis and thrombosis. Other vessels showed conspicuous collagenous thickening, mostly involving the adventitial sheaths (Fig. 5) and some, in silver preparations, bore brush-like tufts of reticulin fibres that extend from the adventitia in to the adjacent tissues (Fig. 6). All normal cellular components of the white matter had disappeared except the microglial cells. These were in amœboid phases; contained sudanophil material, and were unevenly distributed. For the most part they occupied zones about the necrosis, particularly at the junction of grey and white matter. Extracellular particles of sudanophil lipoid were scattered through the necrotic white matter.

Small fragments of the left temporal bone removed at operation were microscopically of normal texture but showed loss of bone cells from many areas. The loss was patchy and nowhere amounted to frank necrosis of the bone. Osteoblasts were absent from the margins of the trabecula. Apart from an occasional granular myelocyte and a few plasma cells there was complete absence of hæmogenetic tissue from the medullary spaces. These were occupied by spongy connective tissue containing few spindle cells and occasional foam cells. In places a lightly eosinophil coagulum containing filaments of fibrin filled the interstices. The blood vessels were engorged and dilated. Fibrinoid swelling and degeneration was present in the wall of one arteriole, and a second was occluded by thrombus. In some of the medullary spaces the tissue showed degeneration and partial necrosis with pyknosis of the nuclei.

Comment.- Of particular interest in this case is the exacerbation of the neurological disturbance which occurred after the insertion of radium. The focal abnormalities became more marked and symptoms and signs of increased intracranial pressure appeared. The pineal gland was displaced and there was an increase in the protein and cellular content of the spinal fluid. There can be little doubt that these changes were initiated by the $x$-ray treatment, and greatly accelerated by the radium.

It is also of interest that so much improvement occurred at such a long interval after the acute manifestations. This is of importance, because in other cases the changes have been steadily progressive. We have recently observed an almost identical case, not included in this series, in which radiation of a rodent ulcer in the right parietal region was followed after several months by rapidly progressive left hemiplegia and hemianopia, with headache and papillœdema. At an exploratory operation a very similar lesion to that described above was found, and representative portions were taken for histological examination. They showed the same changes as in Case 1. The headache was temporarily relieved by the decompression and the papillœdema resolved, but three months later there was a large, tense cerebral hernia and the patient again began to suffer from headache. He gradually became stuporous and died in coma five months after operation. In this case the changes set in train by the radiation were clearly progressive, were not arrested by operative intervention, and were directly responsible for death.

\section{CASe 2}

Colloid cyst of third ventricle mistaken for glioma extending into left temporal lobe. Subtemporal decompression. X-radiation therapy. Death later from hydrocephalus. Multiple areas of necrosis and softening of brain. (R.I. 16246/43.)

A woman aged 53 years was admitted to the Radcliffe Infirmary, Oxford, on March 13, 1940. She had been in good health until a year before admission, when she 
began to have frequent paroxysmal headaches. In June, 1939, these headaches ceased and did not recur. At this time, however, she began to have peculiar attacks of transient loss of contact with her surroundings : she described such an attack as beginning with a peculiar feeling in the abdomen which surged up over her head, and then she would become "confused" for a few moments. If anyone spoke to her she would not be able to understand, nor could she reply. At times during attacks when she was alone she seemed to hear a voice speaking to her but could never remember what was said. At times too she had a feeling that she was in a different place from that in which she actually was, but the details were not clear enough for identification or recollection. There were no olfactory or gustatory components. Witnesses observed many such attacks and reported that she "went pale and vacant" for a few moments, but there were no convulsive movements and no incontinence. She recovered promptly, and resumed what she had been doing before the attack. There was no headache nor pain of any kind associated with these episodes. In December, 1939, she lost consciousness in two of the attacks, on each occasion for about half an hour. There were no convulsive movements, and no sequels. She admitted to no other symptoms, and she came into hospital for investigation of the attacks which were occurring four or five times a day.

On examination the patient was seen to be a healthylooking middle-aged woman. Her face was somewhat hirsute, and she said that, although it had always tended that way, the growth of hair had been more pronounced in the six months before admission. She gave a good account of herself, and there was no obvious mental impairment. She was right-handed, and there was no aphasia. The general physical examination revealed no significant abnormality. Her blood pressure was $130 / 80$ $\mathrm{mm}$. Hg. Examination of the nervous system disclosed the following abnormalities. Both optic discs were a little blurred but there was no measurable swelling, the appearances being interpreted as being due to a preexisting papillœdema which had resolved. Visual acuity was normal, but there was an incomplete right homonymous hemianopia. There was a very slight weakness of the right side of the face and of the right limbs, but the reflexes were all normal and there was no sensory disturbance.

The cerebrospinal fluid pressure was $160 \mathrm{~mm}$., and the fluid contained $60 \mathrm{mg}$. of protein per $100 \mathrm{c.cm}$. In other respects it was normal. Radiographs of the skull were normal.

From the character of the attacks, the right-sided hemianopia, and the slight right hemiparesis, it was thought that she had a lesion, probably an infiltrating tumour, in the depths of the left hemisphere, but the evidence for location and nature of the lesion was clearly too slight to dispense with a ventriculogram. This revealed a slight symmetrical dilation of the lateral ventricles without lateral displacement. There was a constant filling defect in the roof of the third ventricle, posterior to the foramina of Monro. The appearances were interpreted as being due to a neoplasm in this situation, but to explain the hemianopia and the right hemiparesis it was thought that there must be a lateral extension into the left cerebral hemisphere and that an infiltrating glioma was most probable. On March 19, 1940 , a right temporal decompression was done, as it was considered that the ventricles were too little dilated to make a transventricular exploration of the lesion practicable. She stood the operation well and convalescence was uneventful.

She was given her first course of deep $x$-ray treatment between April 22 and June 17, 1940. (The physical factors were : field size, $8.6 \mathrm{~cm}$. diameter ; $\mathrm{kV}$. 190 ; milliamps 6 ; distance $70 \mathrm{~cm}$. ; filter $1 \mathrm{~mm}$. copper ; thirty treatments at $300 \mathrm{r}(180 \mathrm{r})$, three treatments at 200 r (72 r), through right and left lateral and vertical portals ; total tumour dose 3,492 r.)

She continued to have attacks of the same nature as before her treatment, but in other respects she was well and leading a normal life. When she reported on June 19,1941 , fifteen months after operation, the decompression area was indrawn and there were no neurological abnormalities except the right hemianopia, which was unaltered. She had two further courses of deep $x$-ray treatment through right and left lateral portals only : (1) from Nov. 19, 1940, to Dec. 31,1940 , nineteen treatments at $200 \mathrm{r}(72 \mathrm{r})$, and four treatments at $300 \mathrm{r}(108 \mathrm{r})$, the total tumour dose being $1,800 \mathrm{r}$; (2) from March 12, 1942, to April 10, 1942, twenty treatments at 200 r (72 r), the total tumour dose being $1,440 \mathrm{r}$. The physical factors were the same as in the first course. At the end of 1942 the attacks suddenly ceased, and she was entirely free from symptoms until the end of June, 1943, when she began to complain of loss of energy. Early in July it was noticed that her memory was failing and she began to lose interest in her family, her home, and her personal appearance. At the end of July it was noticed that her gait had become slow and laboured and she was dragging her left leg. By the first week in August she was unable to get up. Her speech became slow, monotonous, and thick, and she seemed to have difficulty in swallowing. She was incontinent of urine and fæces. During the first week of September she ceased speaking altogether although she was not unconscious. She had never complained of headache or any pain.

She was readmitted to hospital on Sept. 24, 1943. Although quite conscious, she was mute and was never heard to utter a sound. She could swallow liquids and semi-solids, but slowly, and would keep food in her mouth for hours if not prompted to swallow it. She was immobile in bed and made no attempt to change her position. She was incontinent of urine and fæces. The decompression area was tense and bulging (her husband said it had been so for about two months before admission) and there was considerable swelling of both optic discs, with hæmorrhages and exudate in the fundi. Her co-operation could not be obtained for assessment of visual acuity or fields, but she seemed to be able to see and the pupils reacted briskly to light. There was profound paralysis of conjugate movement of the eyeballs : movement to the left, upwards, and downwards was lost, although she could look to the right side. There was complete left hemiplegia affecting the face, 

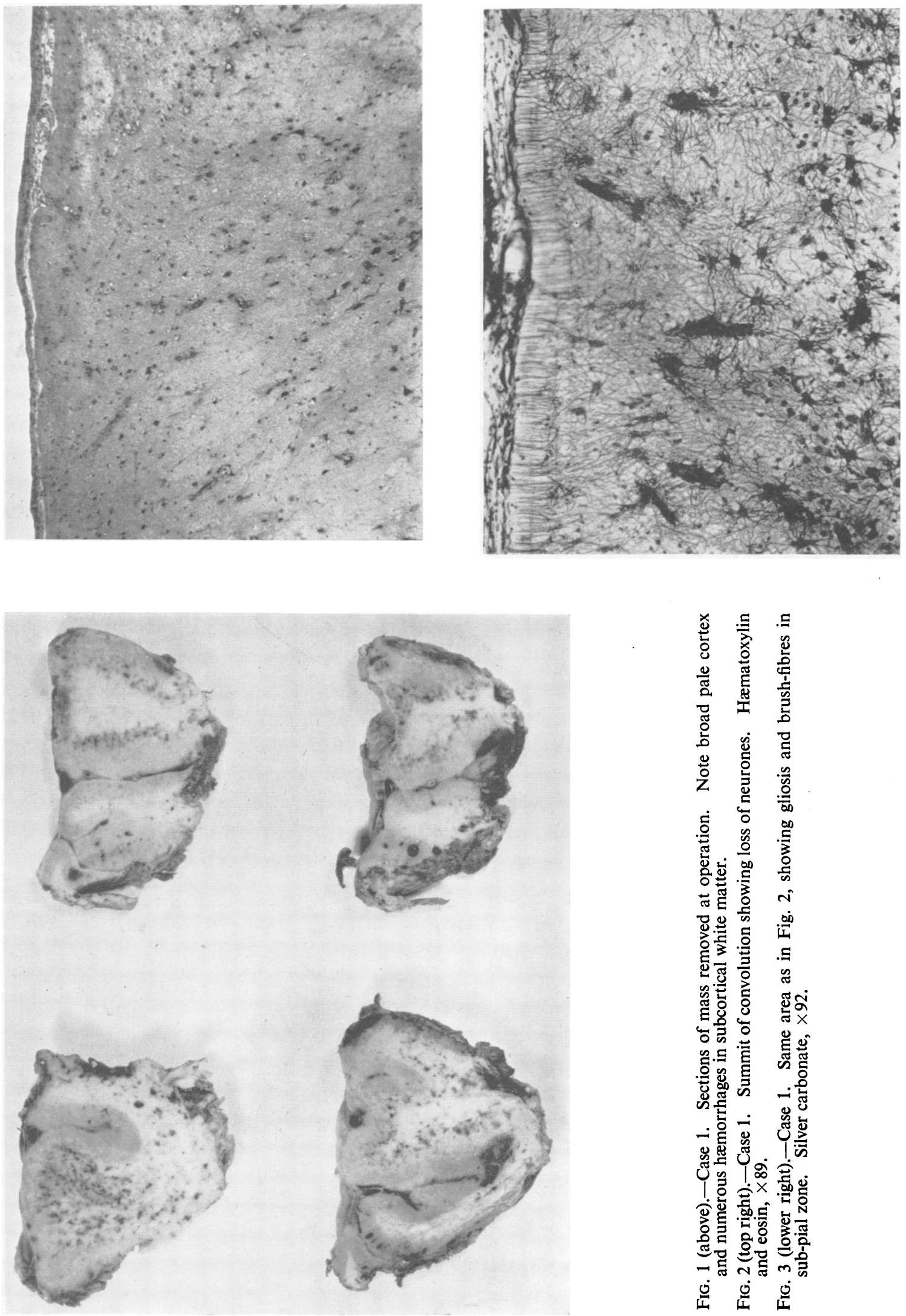

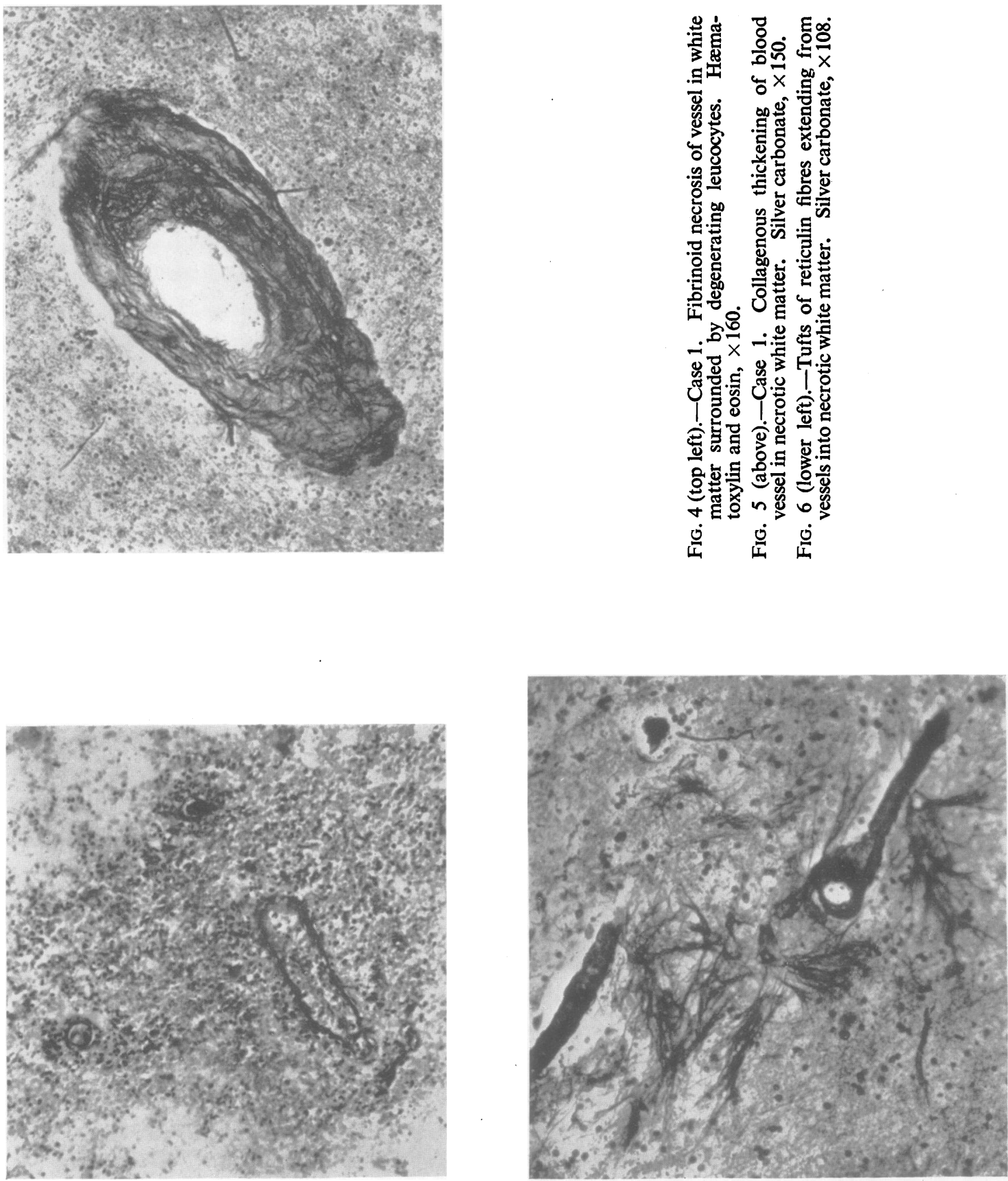


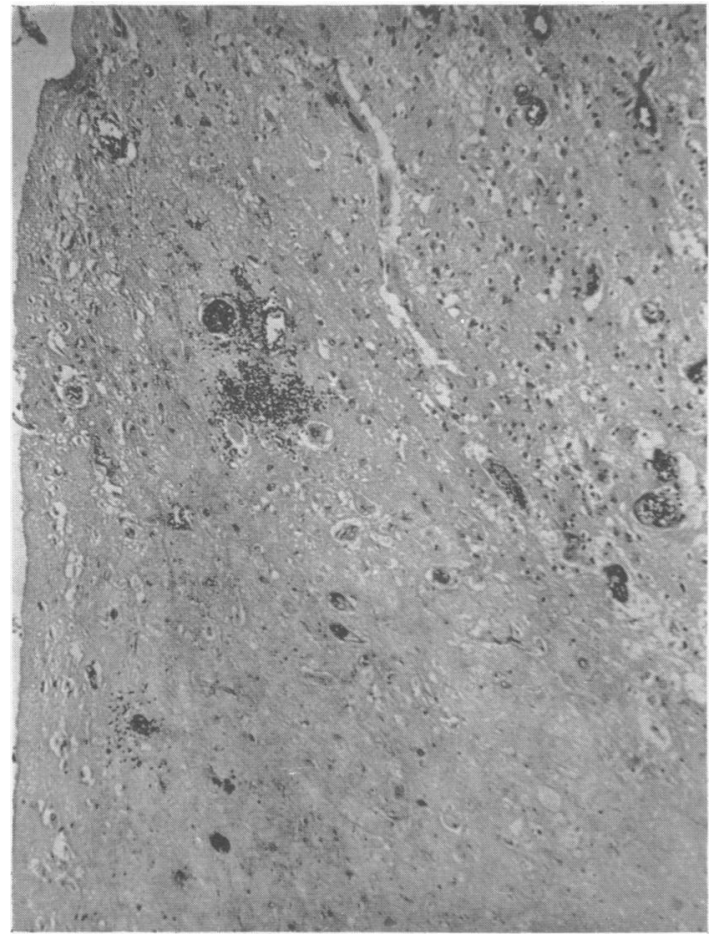

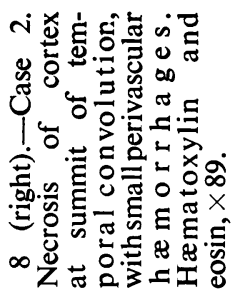

迹

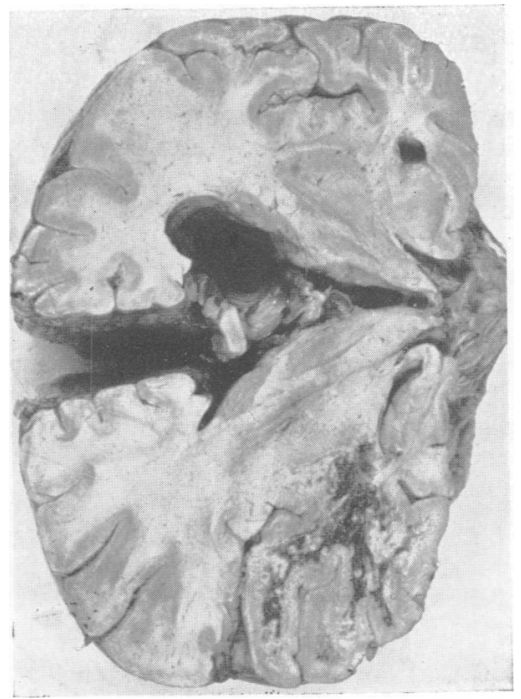

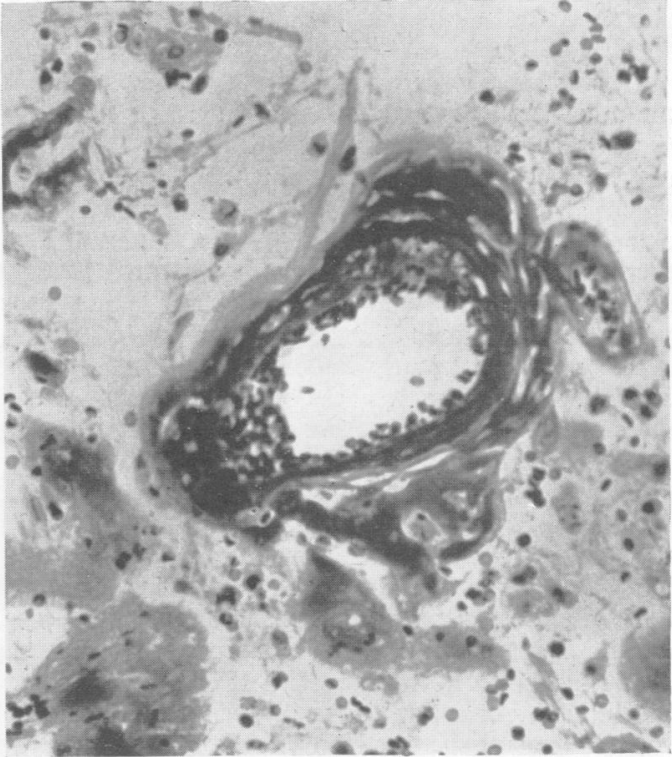

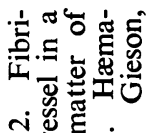

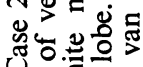

1.

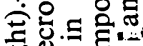
觜 $\geq$

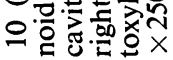

它

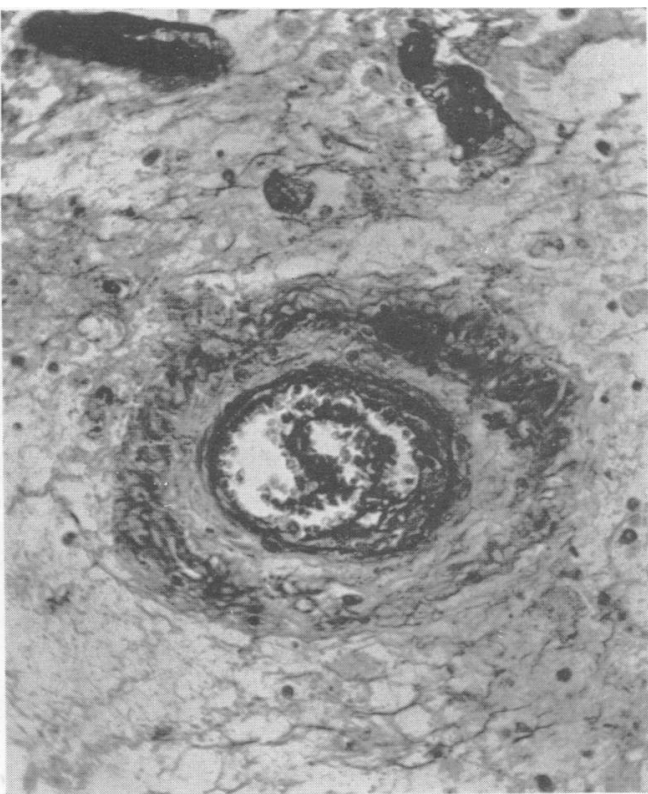


arm, and leg (it was not possible to learn how this had developed, but from the husband's account it was rapid rather than sudden, probably becoming complete between the middle of July and the end of August, 1943). The right limbs were somewhat spastic, and there was involuntary grasping in the right hand. All the tendon reflexes were exaggerated. Both plantar responses were extensor. She seemed to resent painful stimuli less on the left side of the body than on the right. The spinal fluid pressure was $330 \mathrm{~mm}$. The fluid was slightly yellow and contained $80 \mathrm{mg}$. of protein per $100 \mathrm{c.cm}$.

These findings clearly indicated a lesion in the right cerebral hemisphere, whereas on the previous admission three and a half years earlier the evidence pointed to a left hemisphere lesion. The ventriculogram was repeated and this showed dilatation of the left ventricle, with displacement of it and the third ventricle to the left side. The right ventricle was incompletely outlined, but what air was in it suggested a large space-occupying lesion in the central part of the body of the ventricle extending into the thalamus. In searching for the right ventricle, the exploring needle had encountered a small cyst containing a few drops of yellow fluid, and some tough fibrous tissue was recovered from the lumen of the needle. This was spread on a glass slide and stained with toluidine blue. The appearance was that of a fibrillary astrocytoma, and the lesion was considered inoperable. She become more drowsy and died in coma on Oct. 7, 1943.

NeCROPSY EXAMINATION.-At necropsy the brain showed great convolutional flattening. A small colloid cyst, measuring 0.7 by $0.6 \mathrm{~cm}$., occupied the anterior part of the third ventricle, occluding the right foramen of Monro rather more than the left (Fig. 7). There was massive subcortical necrosis of the right temporal lobe beneath the site of the old decompression. This area measured 5.5 by $4.5 \mathrm{~cm}$. in the coronal plane and $6.5 \mathrm{~cm}$. from before back. In most areas the cortex appeared to be intact, though it frequently displayed an ill-defined zone of brownish discoloration along its deep border. Towards the anterior end of the decompression the superficial cortex appeared to be replaced by firm grey tissue. The white matter of the temporal lobe was, for the most part, sunken and brownish and contained many irregular cavities traversed by bands of yellowish necrotic tissue and grey thickened blood vessels. Between this and the cortex was a zone, up to $1 \mathrm{~cm}$. deep, of friable opaque creamy-white necrosis. The necrosis extended into the lower border of the Island of Reil and to within $0.1 \mathrm{~cm}$. of the temporal horn, which was considerably expanded.

There was considerable œedema of the white matter of the right frontal lobe, but the remainder of the cerebral hemispheres appeared normal. In particular there was no macroscopic abnormality in the left temporal region, nor in the tissue at the vertex. At the level of the anterior corpora quadrigemina the lumen of the aqueduct was deforned and displaced to the left, while an ill-defined grey opaque area occupied the site of the right oculomotor nucleus. A similar area, about $0.4 \mathrm{~cm}$. in diameter, was identified in the right side of the tegmental portion of the pons just beneath the floor of the fourth ventricle.

\section{Microscopic Examination}

Right Temporal Lobe.-The right temporal lobe was involved in changes of the same range and character as those described in Case 1. The amount of total destruction of the tissue was, however, greater. Thus the summits of the convolutions at the site of the decompression were entirely devoid of cells, apart from a few subpial astrocytes in advanced stages of degeneration (Fig. 8). Even the perforating blood vessels were for the most part pale and structureless, but a few showed fibrinoid necrosis and retained some of their endothelial nuclei. In the depths of the sulci the necrosis and degeneration were progressively less intense. Swollen fibrillary astrocytes contributed to a gliosis that was less conspicuous than in Case 1, and was found mainly in the deeper laminæ of the cortex. The massive necrosis of the white matter was interrupted by considerable areas of recent hæmorrhage. Irregular cystic spaces often surrounded greatly thickened, hyaline blood vessels (Fig. 9). The presence of macrophages laden with iron pigment in the walls of some of these spaces suggested their origin from antecedent hæmorrhages.

There was great collagenous thickening of the larger meningeal arteries and veins in the sulci. A similar thickening affected the perforating vessels and was more conspicuous than in Case 1, while fibrinoid necrosis of these vessels was on the whole less prevalent, though spectacular when present (Fig. 10). Recanalization of an antecedent thrombus was found in a few perforating vessels.

The white matter in the posterior border of the area was interrupted by large, irregular, often anastomosing areas of necrosis always accompanied by fibrinoi 8 necrosis, and often thrombosis, of the included vessels There was much albuminous hyaline coagulum in the interstices of the adjacent tissue, many large foam cells, and areas in which gliosis is conspicuous. The astrocytes participating in this were greatly swollen and hypertrophied and had long, coarse processes. Many perivascular areas of hæmorrhage were present. A number of vessels, both here and in the more central parts of the necrosis, were cuffed with a mixture of lymphocytes, large mononuclear cells, and foam-cells.

Mid-Brain.-There was œdematous swelling of the right side extending throughout the tegmental region. The vessels were engorged and, in some of the larger meningeal arteries and veins there was recent-probably agonal-thrombosis. Recent perivascular hæmorrhages were present about a few perforating vessels, both dorsal to the right crus and in the grey matter adjacent to the right ventro-lateral border of the aqueduct." An area of anæmic necrosis lay to the right of, and parallel with, the median raphe. A few similar but smaller foci of necrosis, and of œdema without necrosis, occupied the right side of the pons in both basal and tegmental areas. The blood vessels again were engorged. A few minute pericapillary hæmorrhages were present in the tegmental region on the right:

Left Temporal Lobe.-The left temporal lobe was $N$ normal except for a small patch of recent softening in the medial border of the uncinate gyrus. : The softening was 
accompanied by a collection of amœboid microglial cells and local fragmentation of the axis-cylinders with the formation of retraction balls. There was no demonstrable gliosis.

There was no visible abnormality in the cortex and white matter of the left upper Rolandic region.

Clinical Commentary.-It is difficult to relate the necropsy finding of a colloid cyst in the third ventricle to the symptoms for which the decompression and radiation treatment were given. The attacks were regarded as a kind of diencephalic epilepsy, and it is possible that these were due to the hydrocephalus resulting from foraminal obstruction by the colloid cyst, although we have not encountered this symptom in other cases of hydrocephalus due to a colloid cyst. No satisfactory explanation was found for the right hemianopia and the weakness of the right limbs. The irradiation necrosis was doubtless confined to the right temporal region because the bone had been sacrificed at this site, thus permitting the entry here of a greater proportion of the $x$ rays than elsewhere. The changes in the brain stem were of a recent acute character. There was no gliosis. From their position and character it is less probable that they were related to the irradiation of the brain than to disorders of the vascular supply consequent upon increase in intracranial pressure above the tentorium. Equally, the fragmentation of axis cylinders in the white matter and focal softening of the adjacent cortex in the medial border of the left uncinate gyrus are attributable to pressure by the free edge of the tentorium. There was no alteration in the left temporal lobe over its lateral aspect where irradiation of this field might have been expected to produce changes.

\section{Comment on CASEs 1 AND 2}

The similarity of the pathological changes in these two cases is striking. In both there was a massive subcortical necrosis in the irradiated area apparently caused by reactions in the perforating vessels : collagenous thickening, fibrinoid necrosis, and thrombosis of these were all conspicuous features, and relatively few were unaltered. It is remarkable that the meningeal vessels, by contrast, had escaped all but the most trivial alterations. The cortex, though on the whole less affected than the white matter, had lost most if not all of the neurones from the summits of the convolutions without, however, undergoing the atrophy that might have been expected. This lack of shrinkage cannot be satisfactorily explained even if it is assumed that the loss of neurones was, a gradual piecemeal process with a concomitant replacement gliosis. Such a gradual loss is seen in general paralysis and in old age ; in both these conditions cortical atrophy is conspicuous. A further remarkable feature in both these cases was the widespread permeation of the tissue with fibrin. The presence of this change in Case 2 suggests that it was of a persistent character ; it cannot at any rate be interpreted as an operation artefact. Such an escape of fibrin into the tissue must be attributed to an increase in the permeability of the perforating vessels, and this vascular change was said by Scholz and Hsu (1938) to occur in a few weeks after irradiation of the brain. Such an escape of fibrin may support and even expand the cortex and thus counteract the tendency to atrophy. The presence of granules of thorotrast in some of the adventitial cells of the perforating blood vessels in Case 1 is evidence of retarded circulation and increased vascular permeability.

Further peculiarities are to be noted in the glial reactions. Thus the astrocytes partaking in the gliosis were individually of a luxuriance seldom seen except in tumours of these cells. The microglial reaction was, however, disproportionately slight in relation to the degeneration and necrosis. The degree of neuronal degeneration present would ordinarily have been the signal for a conspicuous development of rod cells. But this reaction is in abeyance. It is true that a number of amœboid microglial cells were present but they were, for the most part, confined to areas of frank necrosis or to the borders of such areas. Their processes often presented a stunted appearance and a poverty of development that collectively suggest that these cells are in stages of degeneration as well as activation. The oligodendroglia was not conspicuously altered : in Case 1 there is acute swelling in many areas, while curious hypertrophic forms, not ordinarily seen except in tumours of these cells, were present in the cortex over the summits of convolutions.

In both cases there is histological evidence of a progression of the lesion, shown by the presence of fresh hæmorrhages, and fibrinoid necrosis with recent thrombosis of vessels. While in Case 1 such lesions might be explained by the pre-operative insertion of radium into the adjacent rodent ulcer of the scalp, in Case 2 there is no such clinical factor to explain an outcrop of fresh vascular lesions. There is, however, no means of estimating the age of the lesion or of relating it to the remarkable latent period that elapsed in both cases between the time of irradiation and the onset of symptoms. In Case 1 this latent period was nine months; in Case 2 it was at least sixteen months.

\section{CAse 3}

Right frontal spongioblastoma multiforme. Operation :" partial removal and decompression. Three 
courses of radiation therapy in the next twelve months. Freedom from symptoms in the next five years. Death seven years after operation. Extensive brain necrosis without recurrence of tumour.

L.W., a woman aged 22, came under observation on April 29, 1935, when she was admitted to the National Hospital, Queen Square, London, under the care of Dr. Macdonald Critchley. She had always been in good health until two months before admission, when she had a mild febrile illness regarded as influenza. This illness ran a short course, and after a fortnight she seemed to have recovered, but from about that time she began to complain of right frontal headache. Five weeks before admission she had an epileptic attack initiated by twitching of the left side of the face and the left upper limb. She was unconscious for about thirty minutes, in which time she bit her tongue and was incontinent of urine. When she recovered consciousness she had a very severe headache but there were no other remarkable sequels. From that time she was rarely free from headaches and vomited frequently. One week before admission she had another epileptic attack similar to the first one, and she subsequently noticed some weakness of the left hand.

On admission she was rather thin but did not look particularly ill. Although drowsy she could be roused to give a good account of herself and to co-operate in a full examination. The neurological abnormalities amounted to slight weakness of the left side of the face and the left upper limb. The optic fundi were normal. During the next two weeks she had frequent severe headaches, the optic discs developed $2 \mathrm{D}$. papillœdema, and a few hæmorrhages appeared. The left-sided weakness became more marked and a slight defect in discriminative sense was demonstrated in the left hand. The cerebrospinal fluid pressure was elevated (300 $\mathrm{mm} .+$ ), and the fluid contained $100 \mathrm{mg}$. of protein per $100 \mathrm{c.cm}$., although there was no cellular increase. Radiographs of the skull revealed no definite abnormality.

The evidence suggested an expanding lesion in the right frontal lobe, either a rapidly growing neoplasm, or, because of the relation of the onset of symptoms to an acute febrile illness, an abscess. Mr. Hugh Cairns operated on May 30, 1935, and exposed the right frontal lobe. The convolutions in the lower and posterior part of the frontal lobe were broad and pale, suggesting that the lesion was approaching the surface here, and an incision in the frontal lobe revealed a neoplasm at a depth of $1 \mathrm{~cm}$. from the surface. It had the naked-eye features of a spongioblastoma multiforme. Several portions were removed for histological examination, and sufficient to reduce the intracranial tension. The bone flap was sacrificed, and the scalp closed in the usual manner. Dr. J. G. Greenfield examined the biopsy specimen, and has kindly sent us sections of the tumour. Paraffin sections stained by hæmatoxylin and eosin, hæmatoxylin and van Gieson's mixture, and phosphotungstic-acid hæmatoxylin showed a number of small, irregularly-shaped fragments composed wholly of tumour tissue mixed with blood clot. The tumour was very cellular, and composed of polymorphic cells of vàrious sizes, with indefinite outlines and often separated by a tangle of delicate eosinophil threads. The nuclei of the cells were spheroidal and had a variable chromatin content. Occasional multi- and uninucleate giant cells were present. Mitotic figures were numerous. No definite cytoplasmic fibrils were observed. In places small foci of necrosis were enclosed by palisades of bi-polar cells, and elsewhere similar cells were sometimes orientated towards blood vessels. The tissue as a whole was richly vascular ; endothelial proliferation was conspicuous in many of the smaller vessels. The appearances were those of an undifferentiated malignant glioma with the general character of a spongioblastoma multiforme.

Convalescence was uneventful. The wound healed promptly and there was relief from headache. The papillœdema subsided and there was some improvement in the left-sided weakness. On June 24, 1935, she was transferred to the Mount Vernon Hospital, Northwood, Middlesex, under the care of Mr. Stanford Cade, and had a course of radium treatment by a $100 \mathrm{mg}$. cap applied to the right frontal region : $44,400 \mathrm{mg}$. hours at $4 \mathrm{~cm}$. skin distance. Desquamation took place over part of the skin flap, but there was a steady improvement in her general health and when she was examined on Aug. 30, 1935, the decompression area was soft, the papillodema had subsided, and there was only slight weakness of the left side of the face-and left upper limb.

She remained well until the middle of January, 1936, when she again began to complain of headaches, and the decompression area became very tense. There was and increase in the left-sided weakness, and it was thoughe that this deterioration bespoke renewed activity of tho tumour. She was readmitted to Mount Vernon HospitaB on Feb. 26, 1936, and on this occasion was given a course of high-voltage deep $x$-ray treatment directed to the right frontal lobe $(200 \mathrm{kV} ., 1.5 \mathrm{~mm}$. copper filter $6,600 \mathrm{r}$ in 17 doses through 5 fields, a.p., 2 lateral; superior vertical). This had the effect of relieving the headache to a considerable extent and reducing the tension of the decompression.

On June 19, 1936, she reported that the headache was getting more severe, and that the decompression was "growing." Indeed the hernia cerebri was larger and tighter than it had ever been, and within the few days which elapsed before she was readmitted to Mount Vernon, she had become drowsy, was vomiting frequently, and had developed a complete paralysis of the left upper limb and a partial paralysis of the left side of the face and the left lower limb.

She then had another course of high-voltage deep $x$-ray treatment $(7,800 \mathrm{r}$ through 9 fields, the physical factors as before), and on this occasion there was a dramatic improvement. When she was examined on Oct. 21, 1936, she said that she felt very well. She had had no headache since shortly after beginning the last course of treatment. She was bright and cheerful, and relatives regarded her mentality as normal. The cerebral hernia had diminished until it was flush with the level of the surrounding skull and it was quite soft. The optic discs were flat and visual acuity was normal. There was a slight weakness and sensory defect in the left upper limb, but the facial weakness was hardly 
demonstrable and there was no weakness of the lower limb. On March 5, 1937, there was no striking change except that the decompression area was now markedly indrawn. In July, 1937, she had acute appendicitis treated by appendicectomy without any complications. In February, 1938, it was noted that the left upper limb had improved to the point where there was only a little kinetic weakness of the hand and a slight sensory defect confined to the hand. The decompression area was still markedly indrawn. She returned to full work in a shop, and in June, 1939, she was married.

She remained well, and was leading a normal life until September, 1941, when her left leg suddenly gave way as she was coming downstairs. She did not lose consciousness and thought that she had "turned" her ankle, but when she tried to get up she found that the left leg and arm were completely paralysed. They remained so for two or three days and then began to improve slightly. Recovery was, however, far from complete, and when she was seen on Oct. 4, 1941, she was unable to walk unassisted because of spastic weakness of the left lower limb, while the left upper limb was almost completely paralysed. The decompression area was still markedly indrawn. There was no further improvement, but no definite worsening until February, 1942, when she began to have focal epileptic attacks involving the left limbs and left side of the face. She was readmitted to Mount Vernon Hospital on March 16, 1942 , and had another course of deep $x$-ray therapy $(9,900 \mathrm{r}$ through 5 fields; physical factors as before) to the right frontal region. Except for cessation of the focal epileptic attacks, there was no striking change in her condition, which deteriorated gradually, and she died on July 24, 1942, seven and a quarter years after the onset of symptoms.

MACROSCOPIC EXAMINATION.-The brain with attached dura was received after being hardened in formaldehyde. The right cerebrum was greatly torn and deformed in the preparation of the specimen. Delicate fibrous adhesions united the dura to the lateral aspect of the right posterior frontal region. The leptomeninges were missing from the remainder of the right frontal and parietal lobe to expose an irregular collapsed cavity with soft friable walls involving the whole of the right centrum semiovale with the exception of the tips of the frontal and occipital poles, and the temporal lobe. A narrow zone of subcortical white matter was spared in the posterior frontal and parietal lobes. The softening extended medially to the wall of the lateral ventricle, and partially involved the corpus callosum, fornix, and septum pellucidum. There was no evidence of any residual tumour at the site of the old operation. The cortex here was replaced by firm, granular, greyish-yellow tissue, measuring about $1 \mathrm{~cm}$. in diameter, with a little tougher grey scar tissue flecked with orange pigmentation. No further alteration was found in the brain except slight shrinkage of the right pyramid. The main cerebral arteries were translucent and patent.

Microscopic Examination.-Blocks were prepared from two parts of the scarred operation area in the right frontal lobe, from the lateral aspect of the right frontal and occipital poles to include the wall of the cavity in the central white matter, and from the medulla oblongata. Sections were stained with hæmatoxylin and eosin, Weigert's iron hæmatoxylin and van Gieson's mixture, and phosphotungstic-acid hæmatoxylin.

At the site of the operation scar the cortex was focally replaced by dense hyaline collagenous tissue and fibrillary neuroglia. The adjacent cortex was greatly fragmented, apparently from post-mortem handling, and was extensively necrotic. Many of the clefts present, both in this necrotic tissue and in the scarred tissue, were filled with fibrin filaments, suggesting that potential spaces at least were present in such areas before death. Diffuse areas of infiltration with neutrophil leucocytes and with large monuclear cells containing iron pigment were also present in the necrosis about the scar-tissue. Many of the smaller perforating blood vessels had undergone fibrinoid necrosis and thrombosis. Perivascular hæmorrhages were present about some of these. In the adjacent areas of cortex unaffected by necrosis there was severe dropsical degeneration of the pyramidal cells. The deep layers of the tissue bordering upon the cavity in the central white matter were extensively altered by necrosis and the deposition of fibrin filaments. There was no evidence of any residual tumour.

In the frontal and occipital regions there was everywhere a similar dropsical degeneration of the neurones. A considerable degree of diffuse gliosis was present both in the molecular layer and in the white matter immediately beneath the cortex. There was severe odema of the white matter accompanied by diffuse patches of rarefaction, breaking down in places into irregularlyshaped cavities in which small groups of foam-cells were occasionally found. In the occipital region the white matter was less severely altered than in the frontal. The margins of the central cavity in the white matter in general showed no reaction indicative of an ante-mortem softening. On the other hand the white matter here was entered by occasional clefts, the walls of which were lined in places with fibrillary glia and groups of plump cells of amœboid appearance. The perforating blood vessels were unaltered save for hyaline, collagenous thickening of a small group in the white matter of the frontal lobe. There was fibrous thickening of the leptomeninges accompanied by a moderate infiltration with large mononuclear cells, apparently derived from the arachnoid.

In the medulla oblongata there was slight fibrous thickening of the leptomeninges, with slight lymphocytic infiltration over the pyramids. Beneath the floor of the fourth ventricle a few vessels were cuffed with similar cells. There was partial demyelination with slight atrophy of the right pyramid.

COMMENT.-The most remarkable feature of this case is the proved cure, by combined operative and irradiation treatment, of an example of a highly malignant glioma, spongioblastoma multiforme.

The interpretation of the circumstances leading to the death of the patient is difficult. From the histological appearances of the tissue in the region of the operation area it must be inferred that irradiation necrosis was an important factor: the 
recent necrosis both of cortical tissue and of the perforating vessels, and the extensive escape of fibrin into these tissues, are similar to the changes already described in Cases 1 and 2. But the extensive cavitation of the right hemisphere would seem to be most readily explained as a post-mortem effect based perhaps upon a massive œdema and diffuse degeneration of the white matter, of which indeed there is histological evidence. This œdema and degeneration may well have been a more acute effect of irradiation than the necrosis observed in Cases 1 and 2. The normal condition of the main cerebral arteries excludes an alternative explanation in terms of embolism or thrombosis of the right middle cerebral artery.

\section{CASE 4}

Unverified right frontal glioma. Bony decompression and $x$ radiation. Sudden left hemiplegia one year after operation. Death. (R.I. 16068/41.)

A man aged 37 was admitted to the Radcliffe Infirmary on June 14, 1941. He had been in good health until two months before admission, when he began to complain of headache, fatigue, occasional vomiting, and a feeling of weakness in the left lower limb. One week before admission he began to have frequent attacks of pins and needles in the left thumb and the dorsum of the left hand, occasionally extending to the left lower lip. There was no loss of consciousness, nor any involuntary movements during these attacks.

On examination he appeared to be a healthy man and the general physical examination revealed no abnormalities. The blood pressure was $130 / 85 \mathrm{~mm}$. $\mathrm{Hg}$. He was alert and intelligent and, during several days observation in hospital, he had very little headache although the focal sensory attacks continued. Both optic discs were swollen (2D), but the visual fields were full and the acuity of vision was normal. The positive findings amounted to a very slight weakness and clumsiness of the left lower limb, with increased tendon reflexes on the left side, and an extensor plantar response. There was very slight impairment of two-point discrimination and stereognosis in the left hand. The spinal fluid pressure was $180 \mathrm{~mm}$., and the fluid was normal on analysis. Radiographs of the skull revealed no abnormalities. Ventriculography showed a displacement of the ventricular system to the left side, with some elevation of the floor of the right ventricle in the region of the optic thalamus. It was thought that these appearances indicated a diffuse infiltrating tumour of the right cerebral hemisphere, and a fibrillary astrocytoma was considered the most likely possibility. In view of the patient's slight signs and symptoms, it was decided to do only a bony decompression by means of a right postero-lateral osteoplastic flap, without opening the dura, and to follow this with a course of deep $x$-ray treatment. He stood the operation well ; there were no new neurological developments and he had no headache or epileptic attacks before his discharge on July $7,1941$.

In August, 1941, he had a course of deep $x$-ray therapy directed to the right parietal region. The dosage was $10,500 \mathrm{r}$ through five fields : anterior, posterior right and left lateral, superior, vertical, $250 \mathrm{kV}$., 20 m.a. $1.5 \mathrm{~mm}$. copper filter, $21.7 \mathrm{~cm}$. F-S distance. This produced permanent epilation of the right parietal region of the scalp but there was no burning or ulceration.

He returned to work as a bank manager in September, 1941 , and was subsequently co-opted by a Government department for an important post as inspector of factories. This he did very well, and he led a normal active life, without any headache or epileptic attacks, until June 10, 1942, when he complained of a slight generalized headache which he attributed to overwork. Three days later he had a fit in the street, and was unconscious for a short time. He was taken to hospital where he soon recovered consciousness, but he was left with a partial paralysis of the left side of the body. Four days after this he had another fit which left him with a complete left hemiplegia, and in this state he was readmitted to the Radcliffe Infirmary on July 4, 1942. He was dull and apathetic but could speak in a slow monotonous whisper and he said that he had no headaches. There was no neck stiffness, and Kernig's sign was absent. He was incontinent of urine and fæces. The right side of the scalp was epilated but there was no ulceration. The bone flap was slightly elevated, and there was a low degree of chronic papillœdema. The spinal fluid pressure was $195 \mathrm{~mm}$. He appeared to have a left homonymous hemianopia, probably complete in the upper quadrant. There was no voluntary movement in the left side of the face, or in the left arm and leg. There was some weakness of the right limbs as well, but this was compatible with his apathetic state and his poor general condition. All the tendon reflexes were exaggerated, the left more than the right. The left plantar response was extensor, the right equivocal. There was marked involuntary grasping in the right hand.

The spinal fluid was clear and colourless, and contained $100 \mathrm{mg}$. of protein per $100 \mathrm{c.cm}$. Radiographs of the skull showed no abnormality except the operative defect. . At first the electro-encephalogram revealed a condition of subclinical status epilepticus from a diffuse focus in the right fronto-parietal region (when he was admitted), but the only clinical manifestation was a rhythmical twitching of the left calf muscles and an occasional flicker in the muscles of the left arm. When these phenomena ceased, the electrical discharge was less persistent and of lower voltage. Thereafter, occasional transient subclinical attacks could be picked up, followed by a succession of regular 6 per sec. waves. At other times, there was an irregular discharge of lowvoltage waves from a shifting focus over the right hemisphere.

$\mathrm{He}$ became progressively more stuporose and died in coma on July 19, 1942, one year after operation, eleven months after the $x$-ray therapy, and five weeks after the onset of his final illness.

EXAMINATION OF THE BRAIN.-The inner surface of the dura over the right cerebrum was covered by a tough grey fibrous membrane, up to $0 \cdot 2 \mathrm{~cm}$. thick, diminishing in thickness towards the occipital pole and not continuing on to the falx. There was moderate fibrous 
thickening of the leptomeninges over the corresponding area of the right cerebrum and, less marked, over the vertex of the left cerebrum. About the right Sylvian fissure there was diffuse café-au-lait pigmentation. The right frontal lobe was greatly expanded and, on its mesial aspect, nodules of tumour-like tissue projected from the neighbourhood of the frontal pole to indent the opposing surface of the left frontal lobe.

On coronal section the dorso-medial third of the right frontal lobe was greatly expanded, the white matter in this region showing diffuse opaque .lemon-yellow necrosis while the adjacent cortex appeared swollen, firm, and unusually pale, especially in the superior frontal convolution and medial aspect of the lobe. The junction of cortex and white matter was rendered conspicuous by a zone of greatly engorged blood vessels and petechial hæmorrhages. The area so involved measured 6 by 4 $\mathrm{cm}$. in the coronal plane and about $9 \mathrm{~cm}$. anteroposteriorly; it extended into the genu of the corpus callosum and caused occlusion and ventral displacement of the frontal horn. The remainder of the white matter of the right frontal lobe was œdematous. No further change was found in the rest of the brain, which was congested.

Microscopic ExAmination.-Blocks were prepared from the thickened dura over the right cerebrum and the right frontal lobe at the site of the supposed tumour. Sections were stained by the same methods as in the preceding cases. Frozen sections of the frontal lobe were stained by a variety of silver techniques.

There was great collagenous thickening of the dura including the inner areolar layer. A few groups of macrophages containing iron pigment were present both in the inner layer and between the collagenous fibres of the outer layers. The included blood vessels were engorged, and in some the lumen was reduced by fibromuscular thickening of the intima.

Over the right frontal lobe the leptomeninges showed considerable fibrous thickening. Focal collections of fibrin and a good many vacuolated mononuclear cells were present in the interstices. Slight fibrous thickening of the adventitia of some of the meningeal arteries was the only vascular change present. In the cortex there was considerable diffuse loss of the pyramidal cells accompanied by a proliferation of large fibrillary astrocytes. The appearance was similar to that described in Case 1 but the changes were nowhere so advanced: It was diffuse throughout the cortex forming the summits of the gyri and depths of the sulci. Necrosis was limited to minute perivascular foci where the vessels had undergone fibrinoid necrosis and thrombosis. This vascular change was widespread and was often associated with perivascular zones of fibrin filaments, sometimes accompanied by extravasated red corpuscles. The fibrin did not permeate the tissue so widely as in Cases 1 and 2 . The adventitial sheaths of some of the perforating vessels were infiltrated with small lymphocytes. A few of the larger vessels showed hyaline collagenous thickening with loss of structural characters in their walls combined with similar infiltration.

Relatively few microglial cells could be recognized in the cortex : most of those present were aggregated as amœboid forms, containing sudanophil lipoid, along the borders of the white matter. At more superficial levels in the cortex attempts at the formation of rod cells appeared in places, but many of these cells were apparently degenerating. Few oligodendroglial cells could be recognized; those present were in stages of acute swelling.

The white matter showed complete necrosis with aggregates of degenerating leucocytes in many places, while fibrinoid necrosis and thrombosis affected many perforating vessels, especially those of smaller calibre. Again some of the larger vessels had undergone collagenous thickening with the production of anastomosing leashes of reticulin fibres in the adjacent neural tissue, as seen in Case 1. There was advanced fragmentation of the axis-cylinders.

COMMENT.- In this case, which was studied before any other in this series and at a time, therefore, when we were unacquainted with the effects upon the brain of intensive irradiation, the appearances seen in the right frontal lobe were interpreted as an unusual kind of glioma. To the naked eye it was not unlike some forms of spongioblastoma multiforme. Under the microscope, however, it was clearly of a different character. Provisionally it was thought that the tumour might be a diffuse astrocytoma in which massive subcortical necrosis had been induced by irradiation. In retrospect this diagnosis was supported by the presence of nodular projections from the medial surface of the frontal pole, which might not reasonably be expected in the region of an uncomplicated necrosis of brain tissue. On the other hand the histology was so closely similar to that of Cases 1 and 2 that the possibility has to be entertained that the whole of the area described in this case was of the same character. In this event the precise location of the original tumour. and its ultimate fate remained undecided.

\section{CASE 5}

Focal epilepsy due to left frontal astrocytoma. Decompression. Radiation treatment. Deterioration three years later. Re-exploration and removal of necrotic mass from left frontal lobe. Recovery. (R.I. 20806/42.)

A woman aged 20 came under observation on Jan. 2, 1942 , suffering from focal epilepsy. She was a normal child until at the age of 11 years she was struck on the forehead by a cricket bat. She was dazed, but not unconscious, and nothing was thought of this injury until four months afterwards when she had a succession of attacks of aphasia lasting a few minutes at a time. Two months later the character of the attacks altered : they were ushered in by aphasia (inability to express herself, although she seemed to know what she wanted to say); then the right side of the face, right arm and leg would begin to twitch convulsively, in that order. In some of the attacks she lost consciousness for a few minutes and was dazed for half an hour afterwards. In 
others there was no loss of consciousness. These attacks recurred at irregular intervals but she was rarely free for longer than two months. In the intervals between the attacks she was quite well. She had no headache except for a short time after each attack.

On examination she was seen to be a healthy-looking young woman, and speech and intellect were normal. The optic fundi were normal and the spinal fluid pressure was $85 \mathrm{~mm}$. The neurological examination revealed a very slight weakness of the right side of the face and of the right arm and leg, but there was no difference in the tendon reflexes and both plantar responses were flexor. There was no sensory disturbance. Radiographs of the skull showed a small calcified nodule in the left frontal lobe and the electro-encephalogram revealed a focus of abnormal activity in the same region. A cisternal encephalogram showed a slight displacement of the anterior part of the ventricular system to the right side.

It was thought that the length of the history, the presence and character of the calcification, and the ventriculographic appearances indicated an infiltrating astrocytoma in the left frontal lobe. On Feb. 20, 1942, a left frontal osteoplastic flap was reflected. It was decided to limit the operation to a bony decompression. The dura was not opened, but through it the convolutions in the frontal lobe could be seen to be broadened and pale. To prevent the bone flap from uniting, strips of gutta percha were inserted between the bony edges. She stood the operation well and on March 14, 1942 was sent to Mount Vernon Hospital for a course of deep $x$-ray treatment. This produced permanent epilation of the left frontal region, and there was no definite effect on the character and frequency of the fits.

She was seen at regular intervals thereafter and remained in much the same state until about June, 1945, when she began to deteriorate: the fits became more frequent and severe, and she developed progressive aphasia and progressive weakness of the right arm and leg. She was slower mentally, and complained of a good deal of headache. There was no definite papillœdema, but in addition to moderate aphasia and right hemiparesis there was now some disturbance of sensation in the right upper limb, light touch and stereognostic sense being particularly affected.

The left frontal region was explored again on Feb. 21, 1946. The scalp was thin and relatively avascular. It was tightly adherent to the bone flap, but the gutta percha strips had prevented any union of the bone flap to the skull. The bone flap looked dull and white and it too was avascular with areas of rarefaction visible on its surface. The dura was milky white and thickened, but was not adherent to the brain. The arachnoid over the exposed frontal lobe was less translucent than normal, but the blood vessels on the surface looked quite normal. The convolutions of the exposed brain all looked a little broader than normal, and the middle frontal one in particular was about $2 \mathrm{~cm}$. in width and felt very firm to the touch, whereas the others felt soft. A portion of the frontal lobe was excised including the superior and middle frontal convolutions, extending $7.5 \mathrm{~cm}$. from before back by $6 \mathrm{~cm}$. from side to side, by $4 \mathrm{~cm}$. deep.
It weighed $66 \mathrm{~g}$. The subcortical white matter was very soft, and had a slightly yellowish tinge. In some places there were firm strands of whitish tissue extending from the main mass out into the surrounding white matter. No definite neoplastic tissue was seen. The brain was quite slack after the removal of this mass, and the dura was closed completely, the bone flap replaced, and the scalp closed in the usual manner. The wound healed normally and convalescence was uneventful. There was a transient exacerbation of the aphasia and right-sided weakness following operation, but this improved rapidly and by the time the patient was discharged on March 10, 1946 , the neurological status was virtually the same as on admission. Subsequently she improved in every respect but when last seen in April, 1947, she was still having attacks.

Microscopic Examination.-Microscopic examination of the specimen removed at operation revealed a superficial circumscribed wedge of dense collagenous tissue, embedded in which were numerous islands of glial tissue composed for the most part of bipolar fibrillary astrocytes. The highly cellular character of these islands suggested that they might represent residual tumour tissue. The adjacent convolutions were free from tumour ; in places they appeared normal save for œdema and variable degrees of neuronal chromatolysis, but elsewhere they displayed conspicuous necroses, hæmorrhages, and vascular changes identical with those that have been described in detail in Case 1 .

\section{Discussion}

We believe that the necrotic lesions which occurred in these cases were due to radiation treatment. We have not encountered similar lesions in untreated cases, and there is nothing to suggest that the primary disease for which the treatment was given would predispose to such necrosis : many cases of brain tumour treated by various surgical methods have been examined and no comparable effects have been observed; nor is there any evidence that pre-existing vascular disease contributed to these effects, as in each case the vascular system was normal as assessed by clinical standards and in three cases by necropsy examination.

There are other reports in the literature of similar effects following radiation treatment in human subjects. Fischer and Holfelder (1930) described the case of a patient who had received radiation treatment for a rodent ulcer of the scalp and who seven years later developed focal epilepsy referable to the irradiated site. Biopsy examination revealed destruction of cortical architecture, œdema of interstitial tissue, thickening of intracerebral blood vessels, a "structureless substance resembling hyaline or amyloid" around the vessels, and numerous old hæmorrhages and necroses. These changes are similar to those described in Case 1 of this report. Markiewicz (1935) reported a similar case although the interval between radiation 
and the onset of symptoms was shorter (eighteen months). Scholz and Hsu (1938)-described the changes found in the brains of two deteriorated schizophrenic patients who had been irradiated experimentally eighteen months before death. Their mental state was apparently unaffected, but their general health failed gradually and they became bed-ridden shortly before death. No neurological abnormalities were observed, possibly because of the difficulty of examining such patients. The pathological findings were very similar to those described above, and a photograph of their first case presents much the same appearance as that observed at operation in our Case 1. O'Connell and Brunschwig (1937) observed diffuse degenerative changes in the brains of three patients who had received intensive radiation treatment for intracranial gliomata. They emphasized particularly the effect on normal nerve cells, neuroglia, and microglia, and regarded the changes seen in the blood vessels as of secondary importance. Although their cases had received tumour doses of between 12,000 and $14,000 \mathrm{r}$ (more than most of our cases), the changes which they describe do not seem to have approached the necrosis which occurred in our cases, nor from their report does it seem that the degeneration had any focal distribution, since it occurred widely throughout the brain.

Stevenson and Eckhardt (1945) have described a case of tetraplegia and respiratory paralysis in the spinal cord due to necrosis of the cervical cord after radiation treatment for malignant glands in the neck.

Similar effects have been observed in experimental animals. Lyman and others (1933) irradiated the occipital region of four dogs, three of which were killed within six weeks to study early changes which might be referable to radiation. The fourth animal was killed six months after radiation; in the first five months there were minor alterations in behaviour but no gross physical abnormalities were apparent. Thereafter the animal deteriorated rapidly, showing ataxy, weakness of the limbs, torpor, blindness, and sphincter paralysis. This rapid terminal collapse was in some ways comparable with the clinical course of our Cases 2, 3, and 4. Examination of the brain showed extensive necrosis, maximal in the irradiated field, with degenerative changes in the capillaries and precapillaries, and severe hyaline degeneration and obliterating sclerosis of arterioles. These workers concluded that the harmful effects of radiation were directly referable to changes set up in the blood vessels. On the other hand, Davidoff and others (1938) irradiated a series of monkeys and in some of them produced multiple areas of cavitation with little glial reaction and minimal changes in blood vessels. They regarded these as direct effects of radiation on the parenchyma rather than as the result of vascular lesions. These authors remarked that there may be an interval of four to six months between the radiation treatment and the clinical manifestations of harmful effects. Some years earlier Paterson Ross (1931) produced local necroses in rabbit's brains by implanting radon seeds and radium needles in doses considerably exceeding those employed in therapy. Using smaller doses, he found local degenerative changes in nerve cells and neuroglia, short of necrosis, and although he says that the earliest recognizable response to radiation was in the vascular endothelium, and that hæmorrhage and thrombosis might occur later, he regards the effect on the parenchymatous elements as of major importance.

On the whole our evidence favours the view that the primary effect of radiation is on the smaller blood vessels. The long latent period which may elapse after radiation suggests that the radiation initiates a progressive change in the smaller blood vessels which has the effect of diminishing their lumen, although this may not reach a critical level for many months or years. If the resulting ischæmia is gradual, there would probably be a slowly progressive loss of function, as in Case 2. If the ischæmia developed rapidly, as by thrombosis in already affected vessels, there would probably be sudden manifestations as in Cases 3 and 4 . It seems unlikely that a progressive effect on nerve cells would so long delay clinical manifestations : thus Case 4 was free from symptoms and functionally normal until ten months after radiation and five weeks before death. It may be that there are primary parenchymatous changes which are masked by later vascular lesions, but in the three dogs studied by Lyman and others within six weeks of radiation, the predominant changes were in the smaller blood vessels rather than in the nervous parenchyma.

We have no exact means of determining the incidence of this effect. Three of the cases described above and two others were drawn from a group of 113 patients who had received radiation treatment. We suspect that it is even more common than we have found, because several patients have died in circumstances similar to those we have described, but necropsy examination has not been possible. In other cases massive necrosis of the tumour tissue, usually spongioblastoma multiforme, has been found ; but inasmuch as such necrosis is a usual feature in untreated cases it has proved impossible to assess whether it is due to the irradiation. It is probable, too, that many patients who have received radiation treatment for brain tumours 
die from the effects of the tumour before necrotic lesions have had time to develop.

Our purpose in reporting these cases is to call attention to a harmful effect of radiation therapy which if not frequent is by no means rare, and to suggest that a review of current dosages and technique is necessary. Knowledge of the clinical features may explain some problems which have arisen in the past and will continue to face the clinician who is interested in the after-treatment of patients with brain tumours subjected to radiation. Thus a recurrence or aggravation of symptoms is usually regarded as being due to increased growth of the tumour, and that explanation is undoubtedly correct in the majority of cases. Sudden episodes are usually regarded as being the result of hæmorrhage into the tumour, but in our experience this is a rare occurrence. In both groups, the possibility of radiation necrosis should be borne in mind. Although, as in Case 5, it may be necessary to explore the irradiated area before the diagnosis can be established, this would at least prevent further damage being done by subsequent courses of radiation.

The adjustment of dosage and technique is a matter for further investigation by the physicist, radiotherapist, and experimental pathologist. By present standards, the dosage employed in our cases was heavy but not excessive, and none of them had significant damage to the scalp or skull. Nevertheless it is obvious that the effect on the brain may be so damaging that any beneficial effect on the tumour is eclipsed. It remains to be discovered how much radiation the brain will tolerate without necrosis, and-having determined that-to find out whether this upper limit of safety is still effective against the tumour. We do not intend to decry this method of treatment, because with many brain tumours, notably of the glioma group, we think that radiation in conjunction with surgery has a contribution to make : Case 3 represents the longest survival period of any verified tumour of the spongioblastoma multiforme type that we have encountered, and its disappearance must be attributed to the radiation treatment. Yet we feel that $Z_{\mathbb{D}}$ the present technique is uncertain enough in its effects to demand that radiation treatment be given only to verified tumours which are not amenable $\underset{\epsilon}{\epsilon}$ to surgery and for which no further operation is contemplated.

\section{Summary}

1. The clinical and pathological features of five $\stackrel{\overrightarrow{2}}{\overrightarrow{2}}$ cases of necrosis of the brain following radiation therapy are reported.

2. These cases were treated in different centres with accepted techniques and dosages.

3. The clinical effects may come on suddenly, $\frac{5}{D}$ progress to a point, and become arrested ; or they $\triangle$ may come on gradually and lead to death.

4. In each case there was a long latent period $\overrightarrow{0}$ between the radiation treatment and the onset of clinical signs of necrosis. The shortest interval was nine months, the longest five years.

5. The pathology of the necrosis appears to be related to reactions in the smaller blood vessels, in? which collagenous thickening, fibrinoid necrosis, and thrombosis are conspicuous.

6. As it seems impossible to predict in which cases necrosis will occur, it is suggested that radiation should be reserved for inoperable tumours and thos cases in which no further surgical procedures are contemplated.

\section{REFERENCES}

Davidoff, L. M., Dyke, C. G., Elsberg, C. A., a Tarlov, I. M. (1938). Radiology, 31, 451.

Fischer, A. W., and Holfelder, H. (1930). Dtsch. Z. Chir., 227, 475.

Lyman, R. S., Kupalov, P. S., and Scholz, W. (1933). Arch. Neurol. Psychiat., Chicago, 29, 56.

Markiewicz, T. (1935). Z. ges. Neurol. Psychiat., 152, $\overline{0}$ 548.

O’Connell, J. E. A., and Brunschwig, A. (1937). Brain, $\stackrel{D}{\mathbb{D}}$ 60, 230.

Paterson Ross, J. (1931). Brit. J. Surg., 18, 618.

Scholz, W., and Hsu, Y. K. (1938). Arch. Neurol.

Psychiat., Chicago, 40,928.
Stevenson, L. D., and Fckhardt, R. E. (1945). Arch. Path. , 39, 109. 